Research Article

\title{
Reinforcing the Structural Stability of Old Nationally Important Trees with FRP Wraps
}

\author{
Zheong Jun Yi $(\mathbb{D}$ and Junsuk Kang $\mathbb{D}$ \\ Department of Landscape Architecture and Rural Systems Engineering, Seoul National University, Seoul 08826, Republic of Korea \\ Correspondence should be addressed to Junsuk Kang; junkang@snu.ac.kr
}

Received 14 April 2018; Revised 27 June 2018; Accepted 10 July 2018; Published 1 August 2018

Academic Editor: Ulrich Maschke

Copyright (c) 2018 Zheong Jun Yi and Junsuk Kang. This is an open access article distributed under the Creative Commons Attribution License, which permits unrestricted use, distribution, and reproduction in any medium, provided the original work is properly cited.

\begin{abstract}
This study evaluated the structural effects of applying fiber-reinforced polymer (FRP) wraps around their trunks to support old trees of national importance. High wind loads such as windstorms or hurricanes represent a major threat to tall trees, and researchers have assessed the structural behaviors of trees under wind loads using both analytical and experimental approaches. As yet, however, there is no widely accepted method to safely reinforce the structural stability of nationally and historically important tall trees subject to severe wind loads. Traditional reinforcing methodologies can actually damage supported areas as the supports are relatively stiff compared to the main trunk, introducing stressful interactions. FRP materials have high tensile strength, durability, and flexibility; hence, wrapping them around the surface of the tree trunk could enhance the overall stability of a tall tree subjected to high winds without sacrificing the tree's visual aesthetics or damaging the bark. This study applied nonlinear finite element (FE) analyses to evaluate the complex structural behaviors of the wood and FRP wraps, both of which are anisotropic materials. The results revealed that FRP wraps offer a highly effective way to enhance the structural stability of tall trees with minimal cost.
\end{abstract}

\section{Introduction}

Traditionally, tall old trees are reinforced or supported using anchors, wires, hoses, or wooden stakes. However, these conventional methods often degrade the stability of the main trunk of a tree subjected to severe wind loads because the supporting or reinforcing structures (Figure 1) are usually stiffer than the main trunk. The resulting mismatch exerts stress at the point where the supported limb joins the stem, which may result in severe local failure or damage to the areas in contact with the supporting materials [1]. A further issue is that natural monuments such as Jung-yi-pum-song (Figure 2), a very famous pine tree in Korea that is visited by many tourists every year, must also be protected from any large-scale modification or damage that could adversely affect their appearance. The mechanical strength and stability of trees under wind loads have thus been investigated by a number of researchers who have adopted an array of analytical and experimental approaches to discover information that is essential for the development of effective reinforcing methodologies for old, tall trees exposed to high wind loads.

James et al. [2] evaluated the effects of natural wind on root plate tilt for 250 trees, finding that most trees recorded tilt values below $0.5^{\circ}$ and were thus considered stable. Several mathematical models have also been proposed to predict the critical wind speeds at which damage is likely to occur [3-6]. Conditions that lead to branches being broken or trees uprooted can be assessed using pulling or winching tests without incurring invasive damage [7-9]; Chiba [10] proposed a useful simulation model that addresses the effect of a tree's shape on potential stem breakage. In particular, a dynamic analysis overcomes the limitations of a static analysis, which is important as the dynamic interaction between a tree's stem and its branches has a significant impact on the dynamic response of the tree under wind loads [11].

However, none of these earlier analytical studies have taken into account the anisotropic properties of wood and how these interact with the supporting or enhancing 


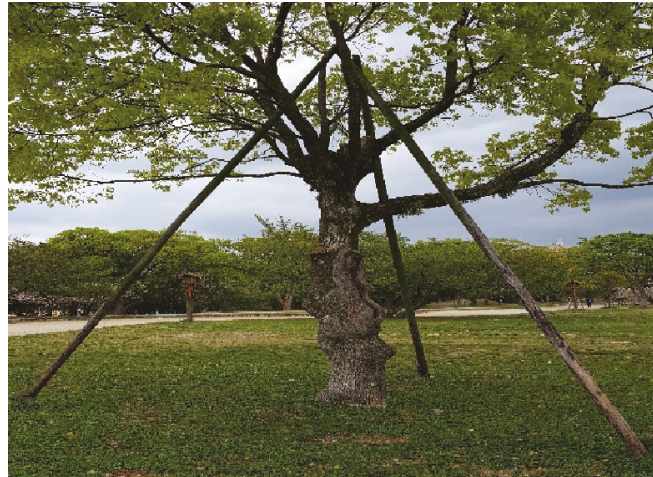

(a) Stakes

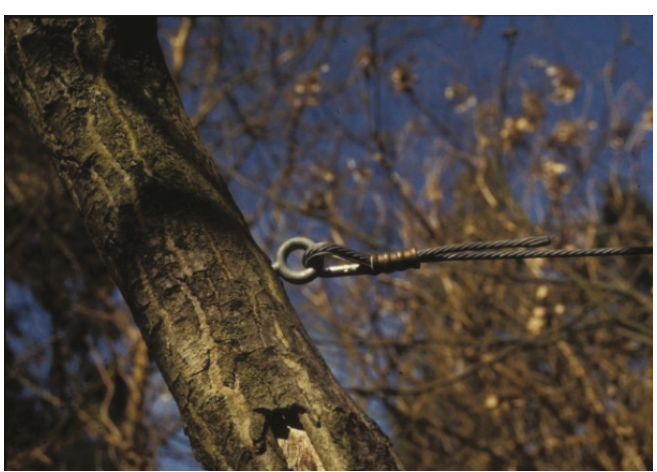

(b) Cabling

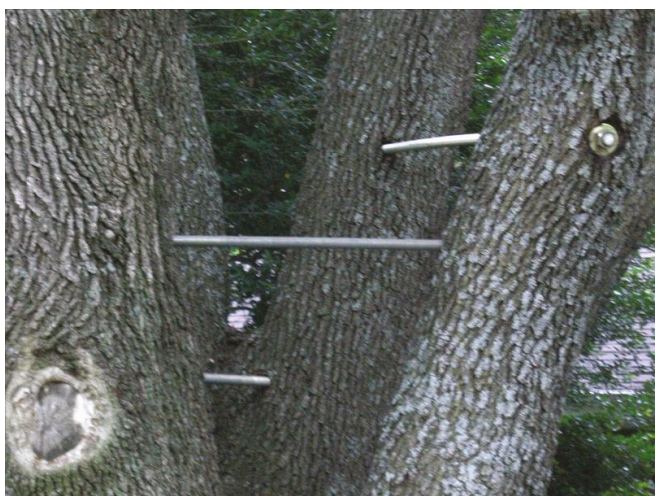

(c) Bracing

FIgure 1: Typical methods of tree reinforcement.

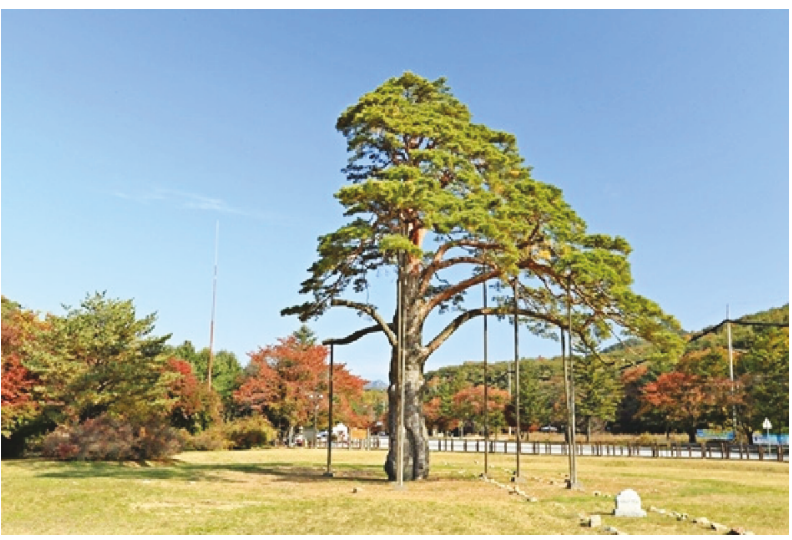

(a) Jung-yi-pum-song (photo by Byun Jong-Man, 2014)

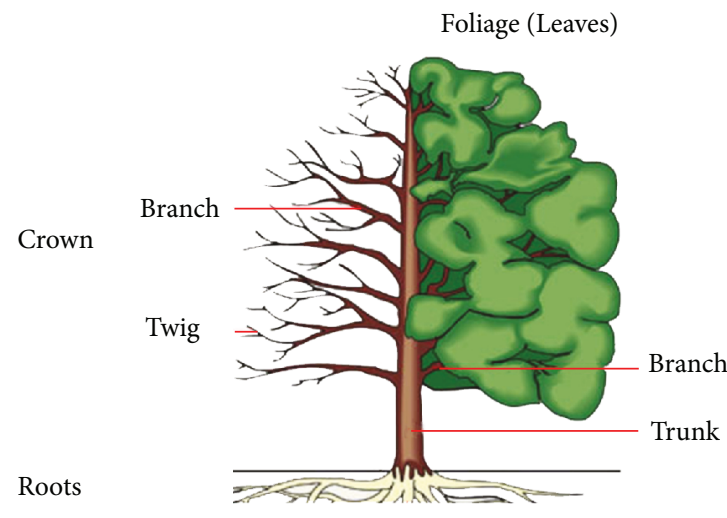

(b) Components of tree

Figure 2: Jung-yi-pum-song (National Monument \#103 in South Korea) and components of tree.

structures or materials introduced. This is especially true for the use of fiber-reinforced polymers (FRP) of the type used in this study, as although they are becoming popular with civil engineers and architects seeking to add strength to structures, this is a relatively new method for tree reinforcement [12-14]. The objective of this study was therefore to analyze the structural effects of using fiber-reinforced polymer (FRP) wraps around the trunk of a carefully preserved old and large tree of national importance that is subjected to high wind loads, taking into account the anisotropic material properties of both the wood and the FRP wrap material using finite element (FE) models specially developed for this project.

\section{Methodology}

2.1. Finite Element Method. This study utilized FE analysis, a numerical method that has been applied to solve a wide variety of problems in engineering and mathematical physics 


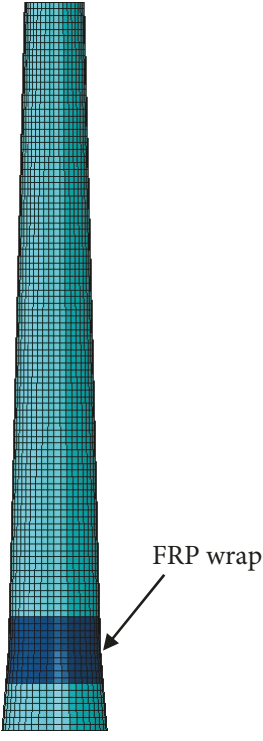

(a) Stem reinforced by FRP wrap

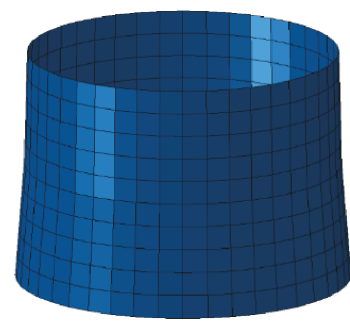

(b) FRP wrap

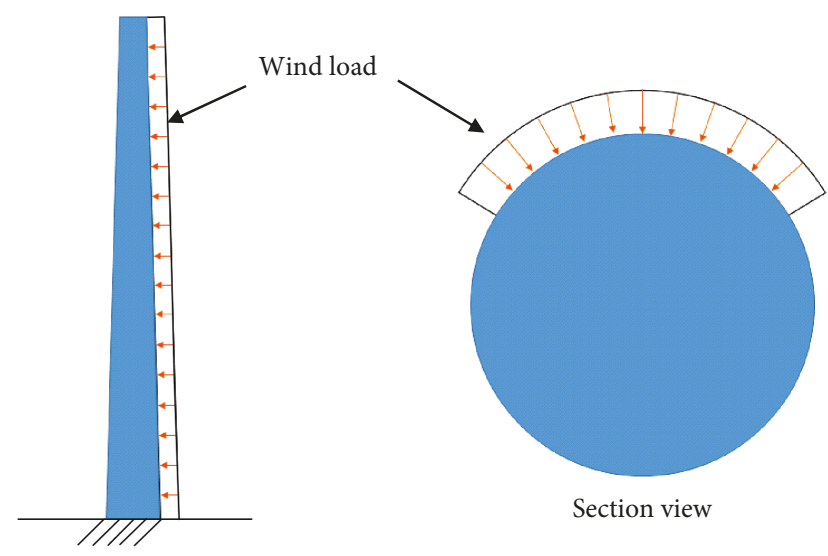

Fixed boundary condition

(c) Loading and boundary conditions

FIGURE 3: Finite element models for the tree stem and FRP wraps.

[15]. The FE method formulates the equations for each finite element and then combines them to obtain a solution for the whole body rather than trying to solve a highly complex problem for the entire body simultaneously. Various FE models have been developed to evaluate the structural behaviors of tree-FRP wrap systems subjected to high wind loads based on the Abaqus FEA software [15]. The schematic FE models for an individual tree stem and the FRP wrap applied to strengthen it are shown in Figures 3(a) and 3(b). The tree stems and FRP wraps are modeled using 3D solid elements (C3D8, which is an 8-node linear brick) and quadrilateral shell elements (S4, a 4-node doubly curved general-purpose shell), respectively, both from the Abaqus element library.

In this study, nonlinear incremental analyses of tree-FRP wrap systems subjected to wind loads have been performed considering material nonlinearity of wood and FRP materials, as well as the geometric nonlinearity involving the equilibrium about the deformed shape of the system. Geometrically nonlinear static problems of the system involve large plastic deformations. It, therefore, is crucial to find static equilibrium states during these unstable phases of the behaviors, which can be effectively found by using the Riks method [15]. Abaqus utilizes the Riks method for nonlinear postfailure analysis. The basic algorithm adopted by the Riks method is basically the same as the one used in Newton's Raphson method, except that the load magnitude is utilized as an additional unknown to find simultaneously for loads and displacements [15].

2.2. Modeling Assumptions. The primary objective of this study was to evaluate the structural effects of FRP wraps applied to a large, old tree subjected to high wind loads. In order to investigate the fundamental mechanism of
TABLE 1: Specification of Jung-yi-pum-song [16].

\begin{tabular}{lc}
\hline Item & Value \\
\hline Species & $\begin{array}{c}\text { Japanese red pine } \\
\text { (Pinus densiflora) }\end{array}$ \\
Total tree height $(\mathrm{m})$ & 16.0 \\
Crown spread $(\mathrm{m})$ & \\
$\quad$ East-West & 13.70 \\
$\quad$ North-South & 18.1 \\
Circumference at root collar $(\mathrm{m})$ & 4.9 \\
Circumference at breast height $(\mathrm{m})$ & 4.3 \\
Height of the lowest branch $(\mathrm{m})$ & 4.72 \\
Age (years) & $\sim 600$ \\
\hline
\end{tabular}

tree-FRP systems effectively, the models developed in this study were based on the following assumptions:

(i) The crown, including both the branches and twigs, has not been modeled.

(ii) The roots are firmly fixed to the ground.

(iii) The interface properties between the trunk and the FRP wraps are for the fully bonded condition.

(iv) Wind pressure is assumed to be uniformly distributed along the height of the tree trunk.

2.3. Modeling Shape. The shape of the tree upon which the model was based takes the geometry of Jung-yi-pum-song (Figure 2), which has values of $10.9 \mathrm{~m}, 0.78 \mathrm{~m}$, and $0.684 \mathrm{~m}$ for the height, root, and breast radii, respectively. The top radius of the tree is assumed to be $0.444 \mathrm{~m}$, as any portion having a radius less than this value will have an insignificant effect on the overall structural behavior of the tree under 


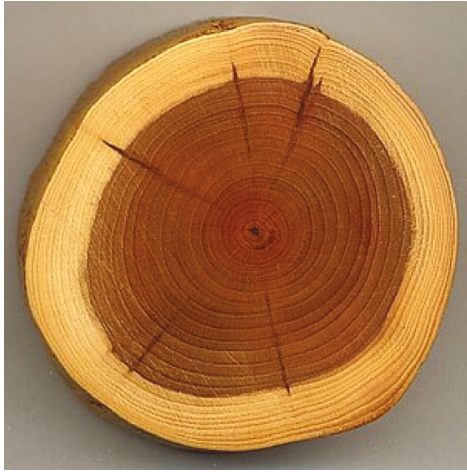

(a) Typical section of wood [17]

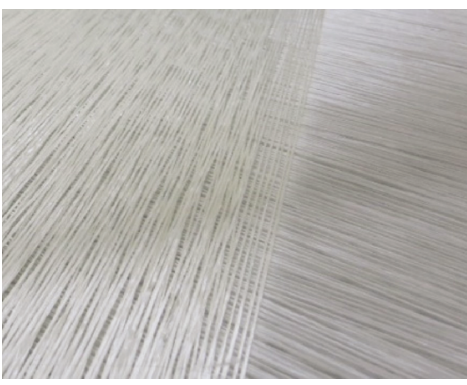

(b) Glass fiber yarn [19]

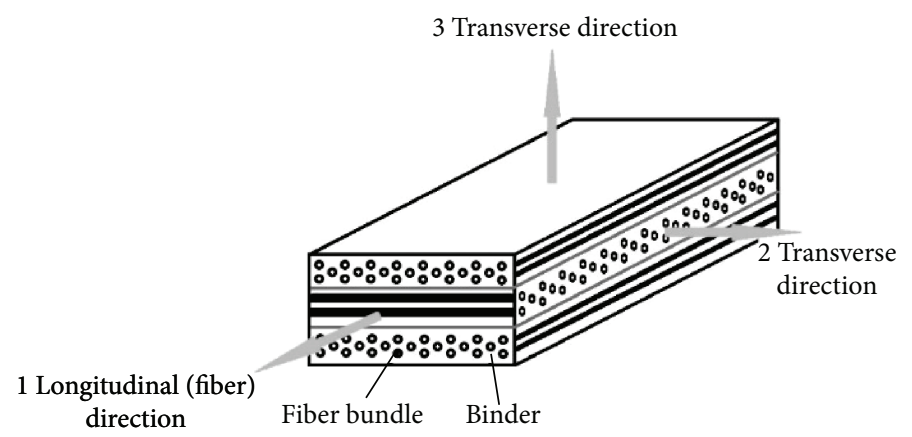

(c) Lamination of FRP wrap

FIGURE 4: Configurations of (a) wood, (b) FRP, and (c) an FRP wrap.

wind loads. The specifications for Jung-yi-pum-song are summarized in Table 1 [16]. As shown in Figures 3(a) and $3(\mathrm{~b})$, the FRP wraps are assumed to be shaped to fit the outer surfaces of the tree at the specified locations.

2.4. Material Modeling. The mechanical properties of wood and composite materials are direction-dependent; such materials are referred to as anisotropic. Orthotropic materials, which have material properties that differ along three mutually orthogonal twofold axes of rotational symmetry [17], are a subset of anisotropic materials.

In this study, wood is modeled as an orthotropic material (Figure 4(a)) as its material properties in three perpendicular directions (axial, circumferential, and radial) are different [18]. Jung-yi-pum-song is categorized as Pinus densiflora, the properties of which have not yet been published in the literature. As an interim measure, for this study the material properties of red pine (Pinus resinosa), which has similar characteristics to Pinus densiflora, were used instead (shown in Table 2, [19]). The density, yield stress, and ultimate strength of red pine are assumed to be $4 E-7 \mathrm{~kg} / \mathrm{m}^{3}$, $2.468 \mathrm{MPa}$, and $3 \mathrm{MPa}$, respectively.

Glass FRP was selected as the material used for the wraps in this study, as shown in Figure 4(b) [20]. FRP laminate is composed of multiple fiber sheets sandwiched together with resin. The properties for glass FRP used in this study are summarized in Table 3. The density, yield stress, and ultimate strength of glass FRP are assumed to be $1.9 E-6 \mathrm{~kg} / \mathrm{m}^{3}$, $1000 \mathrm{MPa}$, and $1100 \mathrm{MPa}$, respectively.
TABle 2: Mechanical properties of red pine (Pinus resinosa).

\begin{tabular}{lccc}
\hline Tensile modulus (MPa) & $E_{\mathrm{L}}$ & $E_{\mathrm{T}}$ & $E_{\mathrm{R}}$ \\
& 9680 & 425.92 & 851.84 \\
\hline \multirow{2}{*}{ Shear modulus (MPa) } & $G_{\mathrm{LR}}$ & $G_{\mathrm{LT}}$ & $G_{\mathrm{RT}}$ \\
& 929.28 & 784.08 & 106.48 \\
\hline \multirow{2}{*}{ Poisson's ratio $(\mathrm{m} / \mathrm{m})$} & $v_{\mathrm{LR}}$ & $v_{\mathrm{LT}}$ & $v_{\mathrm{RT}}$ \\
& 0.347 & 0.135 & 0.408 \\
\hline
\end{tabular}

TABLE 3: Material properties of glass FRP.

\begin{tabular}{lccc}
\hline Tensile modulus (MPa) & $E_{1}$ & $E_{2}$ & $E_{3}$ \\
& 44,240 & 4801.06 & 851.84 \\
\hline Shear modulus (MPa) & $G_{12}$ & $G_{13}$ & $G_{23}$ \\
& 2606.64 & 2606.64 & 1808.06 \\
\hline Poisson's ratio (m/m) & $v_{12}$ & $v_{13}$ & $v_{23}$ \\
& 0.252 & 0.252 & 0.328 \\
\hline
\end{tabular}

The fiber orientation and stacking sequence (lay-up) are the main variables affecting the structural characteristics of the FRP wraps (Figure 4(c)). This study adopted a $0^{\circ} / 90^{\circ}$ lay-up sequence when modeling the FRP wraps: In a unidirectional FRP laminate $\left(0^{\circ}\right)$, the fibers in the laminate run parallel to the hoop direction of the stem, and in a $90^{\circ}$ laminate, the fiber runs parallel to the longitudinal direction of 


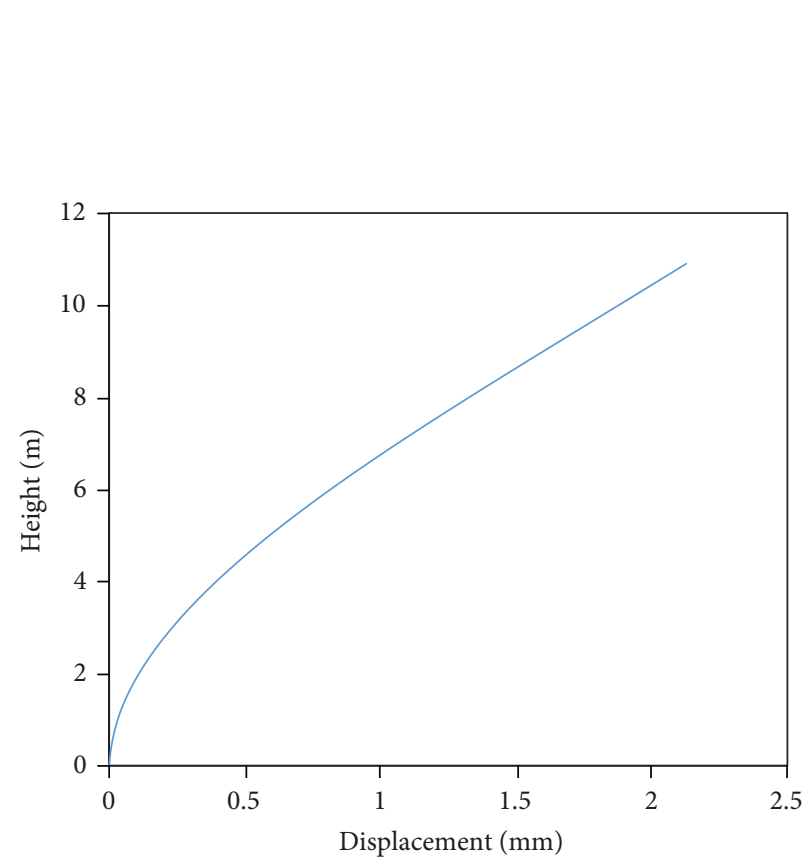

(a) Lateral displacement

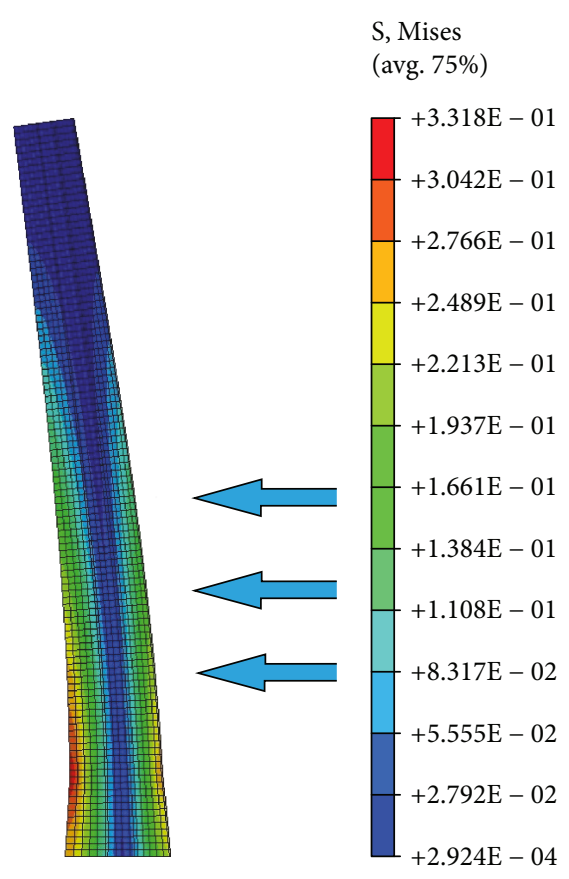

(b) Stress contours

FIgURE 5: (a) Lateral displacements and (b) stress contours along the height of an unreinforced tree stem subjected to a wind load.

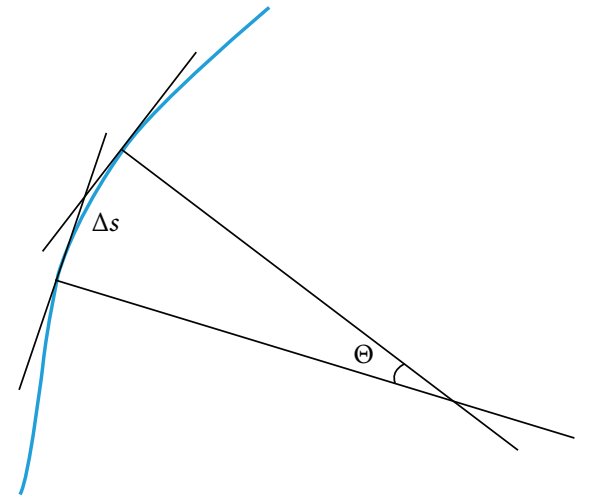

(a) Curvature

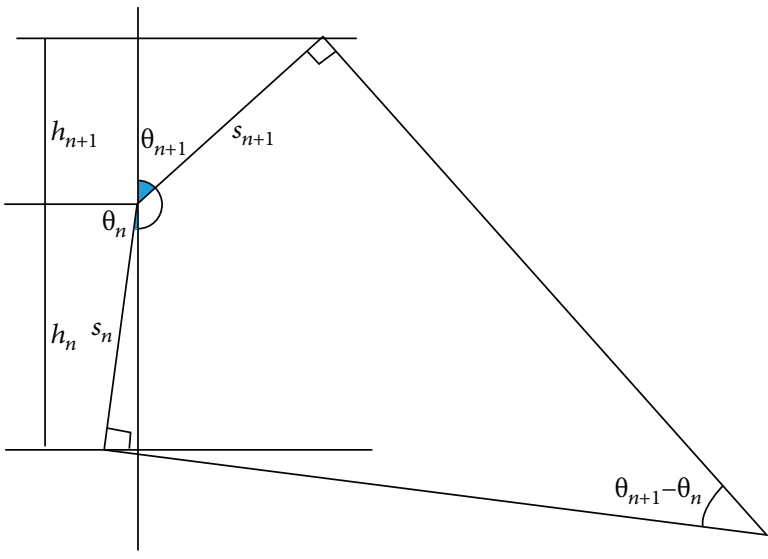

(b) Curvature approximation

FIgURE 6: Schematic diagram for curvature approximation.

the stem. For example, if three layers were used in the FRP wraps, the lay-up sequence for each would be $0^{\circ} / 90^{\circ} / 0^{\circ}$.

2.5. Applied Wind Loads. The strongest factors affecting tree stability are wind and storms. The pressures applied on the FE models were calculated using the following equation:

$$
P=\frac{C_{\mathrm{d}} \rho V^{2}}{2}
$$

where $P, C_{\mathrm{d}}, \rho$, and $V$ are, respectively, the wind pressure, drag coefficient (0.82 for a long cylinder, [21]), air density $\left(1.25 \mathrm{~kg} / \mathrm{m}^{3}\right)$, and air speed.
The strongest winds experienced in the Korean peninsula occur when a typhoon hits South Korea. The wind speeds typically associated with typhoons were thus applied for the analyses in this study. Historically, the maximum instantaneous wind speed of any typhoon observed in Korea was $60 \mathrm{~m} / \mathrm{s}$ [22], which was recorded for Typhoon Maemi on September 12, 2003. An applied wind pressure of 1.845 MPa, which corresponds to the maximum value measured during Maemi, was thus applied to the surface of the tree trunk in our model using [13]. In order to minimize the influence of the components acting perpendicular to the wind direction, the wind pressure was assumed to be applied only to the wind facing side for the purposes of this study, with the wind 


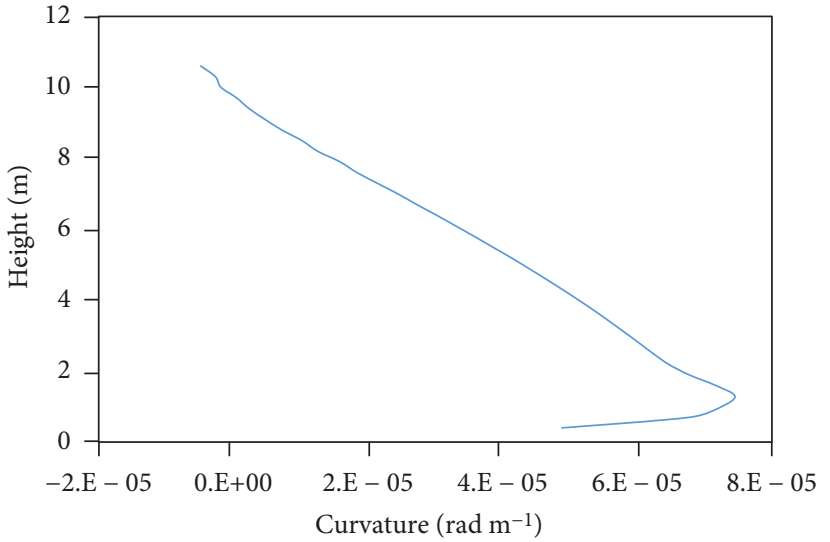

(a) Curvatures

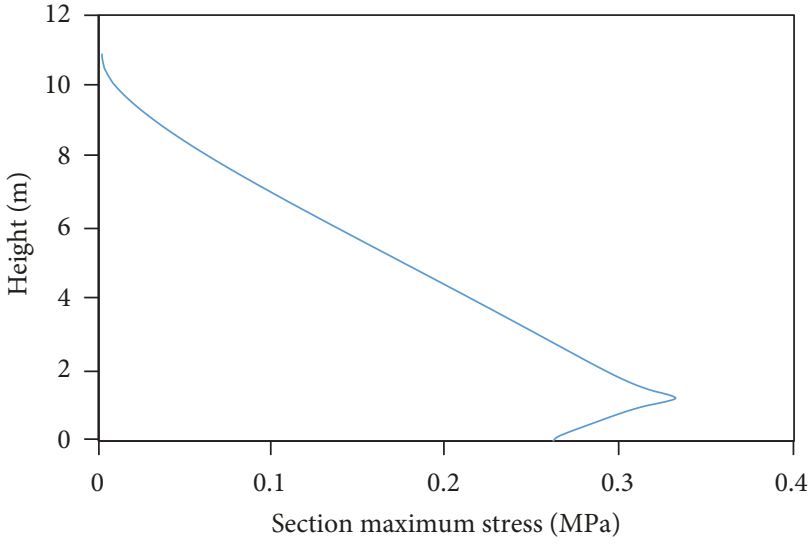

(b) Maximum stress on each section

FIgURE 7: Curvatures and section maximum stresses along the height of an unreinforced stem subjected to a wind load: (a) curvatures and (b) maximum stress on each section.

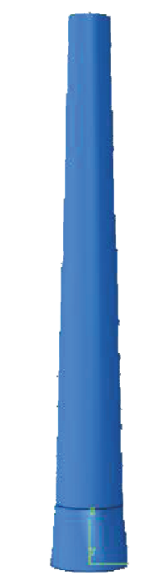

Control model

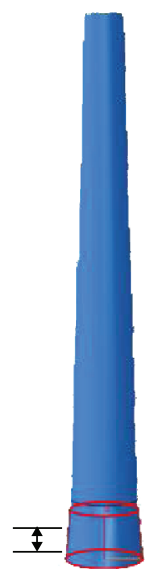

$h=0.5$

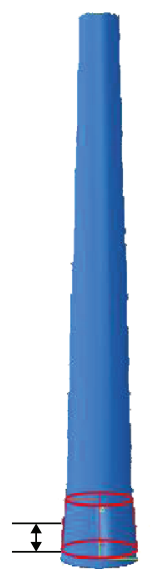

$h=0.7$

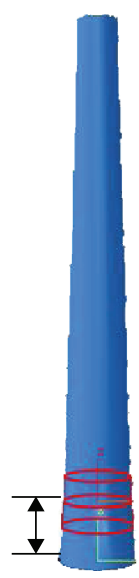

$h=1.2$

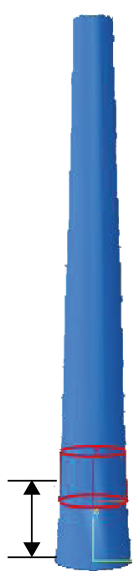

$h=1.7$

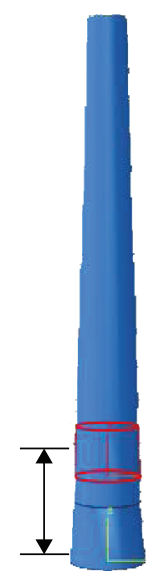

$h=2.2$

FIGURE 8: Locations of FRP wraps used for the analysis $(\mathrm{h}=$ mid-height of FRP wrap, unit: $\mathrm{m})$.

pressure being applied to a $\pi / 3$ region on the windward side around the central axis as a boundary condition, as shown in Figure 3(c).

\section{Results and Discussion}

3.1. Stem without FRP Wraps. Figure 5 shows the lateral displacements and stress contours along the height of the trunk when subjected to a pressure of $1.845 \mathrm{MPa}$ induced by the wind load. The maximum value of the displacement is just $2.13 \mathrm{~mm}$, far less than expected, likely because the effect on the crown of tree was not included in the model [23]. The data presented in Figure 5 show that the curvature and stresses on the lower part of the stem, especially around breast height, are greater than those higher up the stem. As tree failure is largely governed by the bending curvatures of the stem, it is essential to accurately evaluate the curvature if we are to develop a good understanding of the structural behaviors of trees under high wind loads. Figure 6 shows a schematic diagram of the notations for curvature. Curvatures can be approximately calculated using the following equation:

$$
\kappa_{n}=\frac{1}{R}=\lim _{\Delta s \rightarrow 0} \frac{\Theta}{\Delta s} \approx \frac{\theta_{n+1}-\theta_{n}}{s_{n+1}+s_{n}}
$$

where $\kappa_{n}$ is the curvature and $R$ is the radius of the curvature.

Figure 7(a) shows the calculated values for the curvatures $\left(\kappa_{n}\right)$ along the stem according to the height for an unreinforced tree; the highest value occurs at a height of $1.2 \mathrm{~m}$ above the ground, namely, the breast height of the tree. This indicates that the maximum curvature or yield point of an unreinforced tree under pressure will be induced at the breast height of the tree. Figure 7(b) shows the maximum stresses along the height of an unreinforced tree. Here again the maximum stress $(0.332 \mathrm{MPa})$ is at breast height, coinciding with the point of maximum curvature. The maximum compressive stresses on the opposite side of the stem are generally higher than the tensile stresses experienced on the surface directly contacted by the wind, with the maximum 


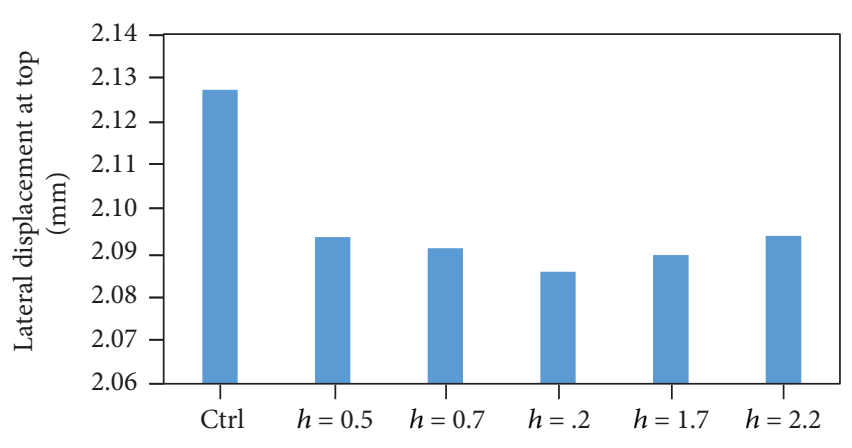

(a) Lateral displacement at top

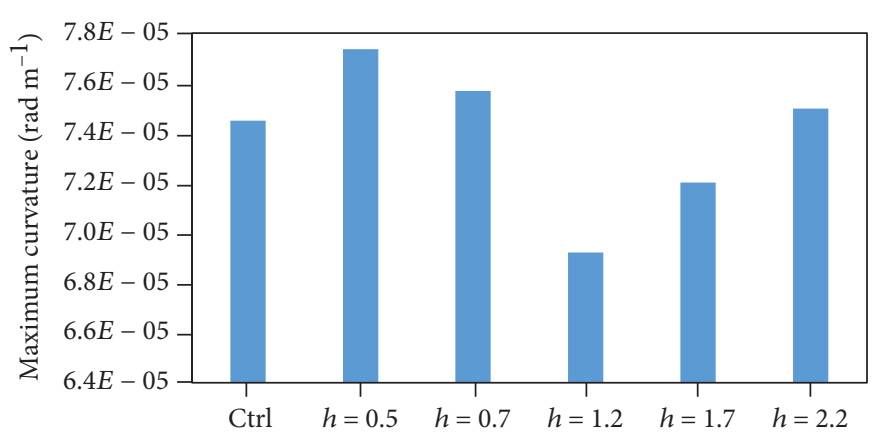

(b) Maximum curvature

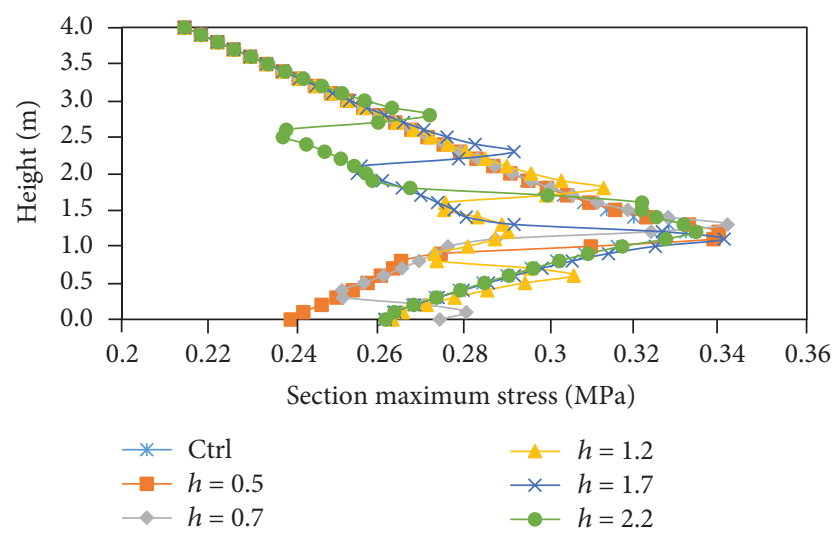

(c) Section maximum stress

FIGURE 9: Effects of different FRP wrap locations: (a) lateral displacement at the top of the stem, (b) maximum curvature, and (c) section maximum stress (Ctrl = stem model with no FRP wraps; $h=$ mid-height of FRP wrap, unit: $m$ ).

compressive and tensile stresses computed to be $0.332 \mathrm{MPa}$ and $0.280 \mathrm{MPa}$, respectively.

3.2. Stem Reinforced with FRP Wraps. The location, thickness or number of layers, and size of the FRP wraps are the primary parameters potentially affecting the structural behaviors of tall trees exposed to a $60 \mathrm{~m} / \mathrm{s}$ wind. For the purposes of this study, we assume there is a fully bonded interface between the outer surface of the tree (i.e., its bark) and the inner surface of the FRP wrap.

3.2.1. Effects of Different FRP Wrap Locations. The effects of various FRP wrap positions were investigated for a single three-layer wrap to determine the optimum locations in order to maximize the enhancement of tree stability achieved. For the calculation, the mid-height of the $1 \mathrm{~m}$ wide FRP wrap was varied over a range from $0.7 \mathrm{~m}$ to $2.2 \mathrm{~m}$ above the ground at intervals of $0.5 \mathrm{~m}$; the case where the bottom of the FRP wrap touched the ground was also analyzed (Figure 8). The control was a trunk with no FRP wraps.

Figure 9 shows how the location of the FRP wrap affects the tree's lateral displacement, maximum stresses, and maximum curvatures along its height. As shown in Figure 9(a), the lateral displacement at the top of the stem is smallest when the midpoint height $(h)$ of the FRP wrap is $1.2 \mathrm{~m}$. The lateral displacements at the top of the tree can thus be reduced most effectively by applying a single FRP wrap at breast height, which is approximately $1.2 \mathrm{~m}$ from the ground.
Looking at the maximum curvatures obtained for the various placements of the FRP wrap, Figure 9(b) shows that applying an FRP wrap at $h=1.2 \mathrm{~m}$ is the most effective for reducing the maximum curvature as well as minimizing the lateral displacement. This is especially important as the maximum curvature is actually more critical than lateral displacement, as stem failure generally occurs due to excessive curvature at the tree's breast height.

Figure 9(c) shows the maximum stresses along the height for the various FRP wrap placements. The stresses in the areas reinforced by FRP wraps decrease significantly, accompanied by stress concentrations at the edges of the FRP wraps The stresses shown in Figure 9(c) show only the values from the bottom to a height of $4 \mathrm{~m}$, as according to the calculations the portions beyond an elevation $(H)$ of $4.0 \mathrm{~m}$ are not affected by wrapping. The maximum stress for $h=1.2 \mathrm{~m}$ is $0.313 \mathrm{MPa}$, the lowest among all the cases tested; the second lowest is $0.314 \mathrm{MPa}$, for $h=2.2 \mathrm{~m}$. Interestingly, the stress at $h=0.7 \mathrm{~m}$ is $0.342 \mathrm{MPa}$, which is higher than the maximum stress experienced by the control model $(0.332 \mathrm{MPa})$. This indicates that applying an FRP wrap below the breast height of the tree could actually be detrimental to the stability of an old, large tree.

3.2.2. Effects of the Number of FRP Wrap Layers. The effect of varying the number of layers in the FRP wrap ( $n)$ was investigated, with the width of the FRP wraps fixed as $1 \mathrm{~m}$ and the midpoint of the wrap located at $h=1.2 \mathrm{~m}$. Wraps composed 


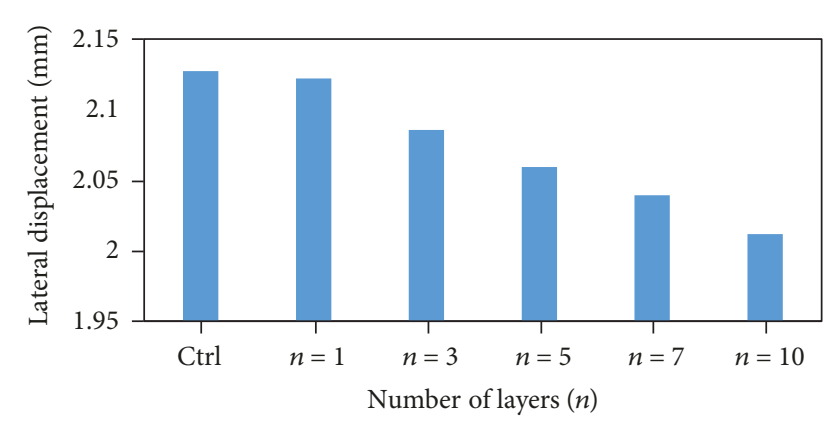

(a) Maximum lateral displacement at the top of the stem

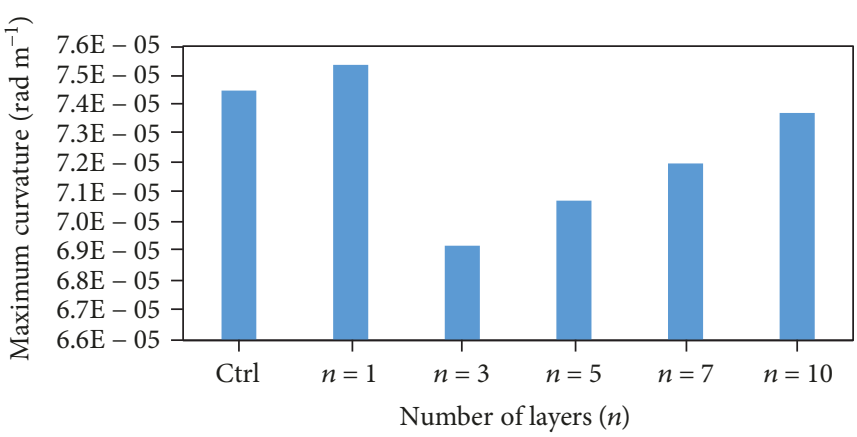

(b) Maximum curvature

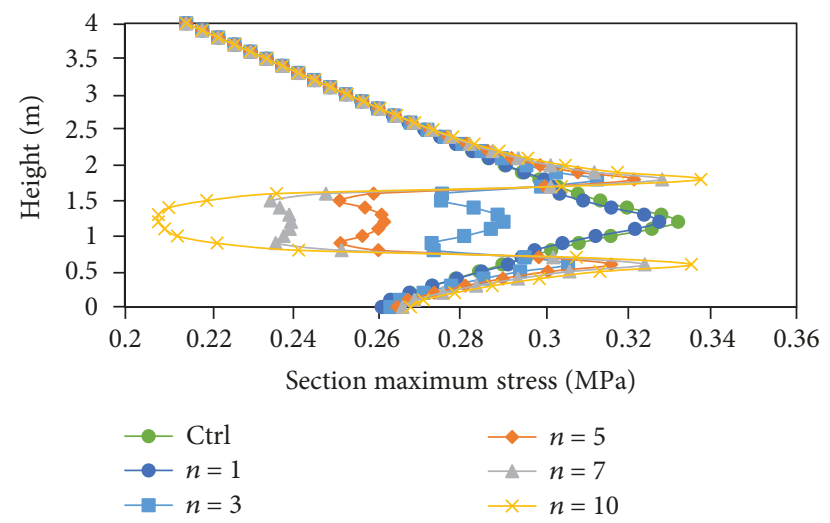

(c) Section maximum stress

FIGURE 10: Effect of the number of FRP wrap layers: (a) maximum lateral displacement at the top of the stem, (b) maximum curvature, and (c) section maximum stress.

of $1,3,5,7$, and 10 layers were tested. Although increasing the number of layers decreased the displacement and stress achieved, the reduction efficiency per layer peaked at 3 layers.

Figure 10 shows the structural effects of the number of FRP wrap layers. As Figure 10(a) shows, the maximum lateral displacement at the top of the stem is reduced by $0.005 \mathrm{~mm}$ when only a single FRP layer wrap is applied, dropping from 2.127, the displacement when no wraps were applied, to 2.122. For a three-layer wrap, the displacement falls by a further $0.036 \mathrm{~mm}$, dropping from $2.122 \mathrm{~mm}$ to $2.086 \mathrm{~mm}$, an improvement of $1.72 \%$ compared to $n=1$. Increasing the number of layers to 5 , the maximum displacement decreases by another $0.026 \mathrm{~mm}$, dropping from $2.086 \mathrm{~mm}$ to $2.059 \mathrm{~mm}$, an improvement of $1.26 \%$ over the reduction obtained for $n=3$. The maximum displacement then decreases by $0.020 \mathrm{~mm}$, an improvement of $0.98 \%$ compared to $n=5$, for a seven-layer wrap. As these results demonstrate, the rate of reduction in the maximum displacements slows slightly as the number of layers increases, with each additional layer achieving a little less than its predecessor.

Unlike the pattern for displacement, the results presented in Figure 10(b) reveal that the reduction in the maximum curvature achieved is not proportional to the number of layers, even though the greatest effect is again achieved with just three layers. As the number of layers increases from three to ten, the maximum curvature also increases. This is likely because the additional stiffness of FRP wraps with more than three layers results in significant stress concentrations at the edges of the FRP wraps (Figure 10(c)), thus increasing their maximum curvatures.

Figure 10(c) shows the maximum stress distributions along the height of the trunk for wraps with various numbers of FRP layers. The graph reveals that the maximum stress at $H=1.2 \mathrm{~m}$ is only reduced by $0.005 \mathrm{MPa}(1.24 \%)$, dropping from $0.332 \mathrm{MPa}$ to $0.327 \mathrm{MPa}$, when a single layer wrap is applied. As the number of layers in the wrap increases to three, the maximum stresses experienced decreases by $0.037 \mathrm{MPa}$ (11.32\%), dropping from 0.327 $\mathrm{MPa}$ to $0.290 \mathrm{MPa}$. However, above this point the efficiencies again start to drop as the number of layers increases. For five layers, the maximum stress decreases by a further $0.028 \mathrm{MPa}(9.78 \%)$ dropping from $0.290 \mathrm{MPa}$ to $0.262 \mathrm{MPa}$, and a further increase to seven layers achieves only another $0.022 \mathrm{MPa}(8.50 \%)$. As the figure shows, the maximum stresses are in most cases generated at the edges of the FRP wraps, with the sole exception being for the case of a single layer, where the maximum stress occurs at the midpoint of the FRP wrap. Interestingly, once the number of layers reaches ten, the maximum stress actually increases by $0.045 \mathrm{MPa}$, which is $15.53 \%$ higher than for the control group. These results indicate that beyond a certain point, increasing the number of layers can actually reduce the stability of a tree subjected to high wind loads. In addition, the data shown in Figure 10(c) suggest that parts of the tree that are some distance from the area stiffened by FRP wraps will not be affected by the number of layers. 


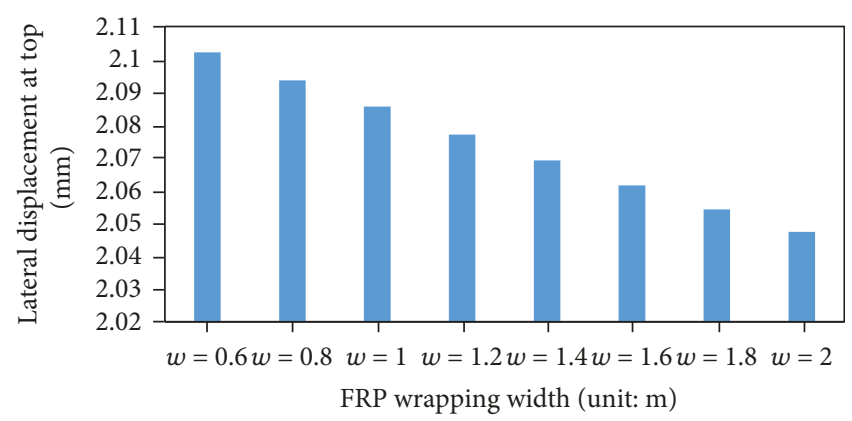

(a) Lateral displacement at top

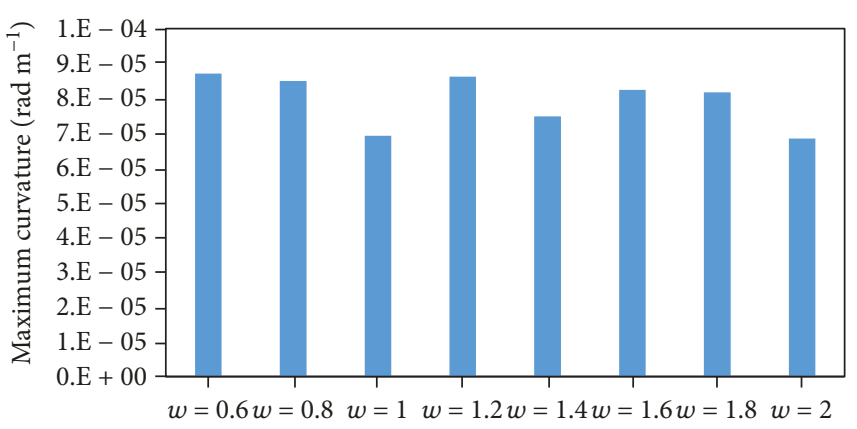

(b) Maximum curvature

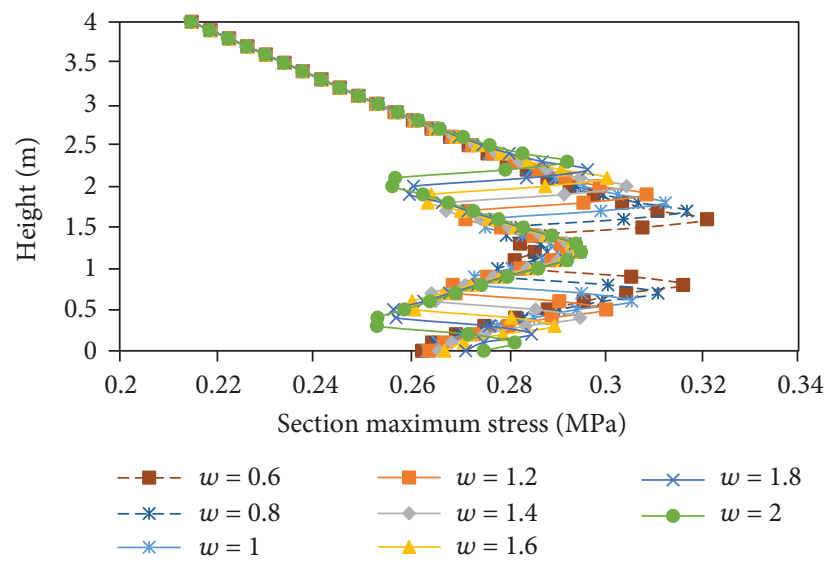

(c) Section maximum stress

FIGURE 11: Effect of the width of the FRP wraps: (a) lateral displacement at the top of the stem, (b) maximum curvature, and (c) section maximum stress. ( $w=$ width of FRP wrap).

3.2.3. Effects of the Width of the FRP Wraps. The effects of the width $(w)$ of the FRP wraps were evaluated for three-layer FRP wraps surrounding the stem at a height $h=1.2 \mathrm{~m}$. The width of the FRP wraps ranged from $0.6 \mathrm{~m}$ to $2 \mathrm{~m}$ in $0.2 \mathrm{~m}$ increments.

The results shown in Figure 11(a) reveal that the maximum displacement achieved gradually decreases as $w$ increases. The rate at which this reduction occurs, however, once again slows down slightly as the width increases, although unlike the results for the displacement, the change in the maximum curvature follows no discernable pattern, as the data presented in Figure 11(b) demonstrate. The $1 \mathrm{~m}$ wide FRP wrap is the most effective at reducing the trunk's maximum curvature under a wind load, outperforming all the other widths, both wider and narrower. Maximum stresses are again induced at the edges of the FRP wraps in most cases, with the sole exception being $w=2.0 \mathrm{~m}$ (Figure 11(c)). As $w$ increases, the maximum stress steadily drops. This is in marked contrast to the trend in the displacements shown in Figure 11(a). Here, as $w$ rises from $0.6 \mathrm{~m}$ to $0.8 \mathrm{~m}$, the maximum stress decreases by $4.16 \times 10^{3} \mathrm{MPa}$ $(1.29 \%)$ and as $w$ goes up from $1.2 \mathrm{~m}$ to $1.4 \mathrm{~m}$, the maximum stress decreases by another $4.11 \times 10^{3} \mathrm{MPa}(1.33 \%)$; similar reduction rates are calculated for the other cases.

Interestingly, even though the maximum stress is at the midpoint of the FRP wrap for the case $w=2.0 \mathrm{~m}$, the reduction rate $(1.42 \%)$ is still close to those obtained for the other cases. In fact, the stress distributions obtained for the areas supported by the FRP wraps were found to be similar in all cases, even when the maximum values and their locations were different as can be seen in Figure 11(c). As the width increases, the stresses at the edges drop slightly and the stresses at the centers slightly increase.

In summary, although the locations and number of layers in the FRP wraps both clearly affect the structural behaviors of a tree-FRP wrap system subjected to wind loads significantly, the effect of the width of the FRP wraps used will be relatively small.

3.3. Postfailure Analyses of Stem with FRP Wraps. The ultimate strengths and yield points for large old trees under severe wind loads were evaluated for this study taking into account not only the material nonlinearities of wood and the FRP materials used but also the geometric nonlinearity caused by changes in the equilibrium due to the deformed configuration of the system. For this analysis, the tree was subjected to a combination of a uniform lateral wind pressure applied along the length of the stem and the self-weight of the stem. The lateral wind pressure was applied on the stem incrementally and the corresponding lateral displacement at the monitoring point calculated. The postfailure behavior of tree-FRP wrap systems will be highly unstable, as large plastic 


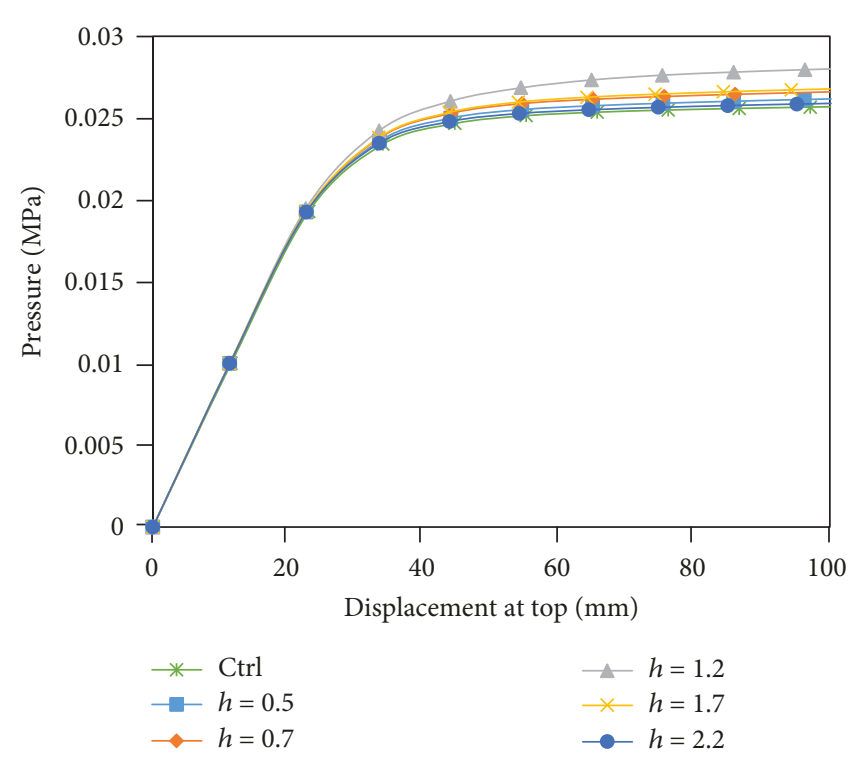

(a) Pressure-lateral displacement histories

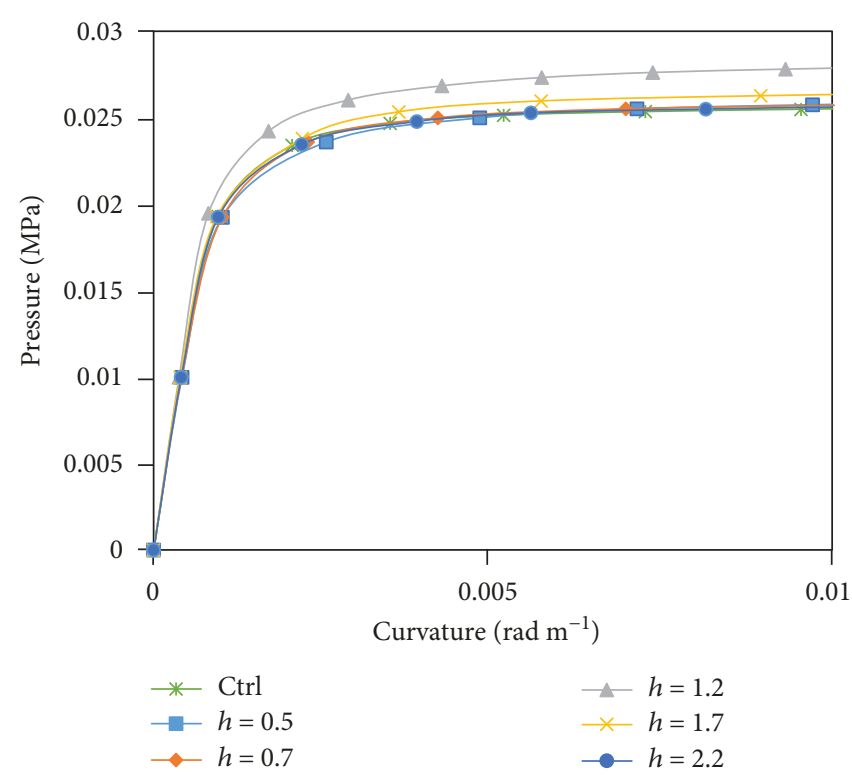

(b) Pressure-maximum curvature histories

FIGURE 12: Nonlinear incremental analyses for tree-FRP wrap systems: (a) pressure-lateral displacement histories and (b) pressure-maximum curvature histories.

deformations are involved. Static equilibrium states during these unstable phases of the responses can be found by applying the Riks method provided in Abaqus [15].

The histories of lateral wind pressure versus the lateral displacement at the top of the stem were plotted for a $1 \mathrm{~m}$ wide, three-layer FRP wrap placed at various locations along the stem (Figure 12(a)). The results show that the stiffness of a tree-FRP wrap system is not seriously affected by the location of the FRP wrap. The ultimate strengths, however, are clearly higher when the FRP wrap is located at breast height, $h=1.2 \mathrm{~m}$. This is not surprising, given that the maximum curvatures under a wind load are also reduced most effectively when the FRP wraps are applied at breast height, as noted earlier. Figure 12(b) shows the pressure-maximum curvature histories for stems supported by FRP wraps with the same characteristics at various locations, with the yield points occurring at around $0.002 \mathrm{rad} / \mathrm{m}$ in most cases. These findings confirm the most effective locations for the FRP wraps indicated by the results reported above as well as identifying the yield points of the stems of large, old trees subjected to severe wind loads. Figure 13 shows the stress contours at the yield point for both the stem and the FRP wraps at $h=1.2 \mathrm{~m}$.

\section{Conclusions}

In this paper, the structural behaviors for a large, old tree enhanced by FRP wraps subjected to severe wind loads were modeled using the finite element method and nonlinear material models. Constant and incremental wind pressures were applied to the stem and the maximum displacement, curvature, maximum stress, ultimate strength, and yielding curvature computed in order to evaluate both the resulting complex postfailure behaviors and the prefailure and yielding stages. Based on the results described above, the following conclusions can be drawn:

(1) Maximum stresses and curvatures for unreinforced stems are induced at breast height $(h=1.2 \mathrm{~m})$, especially on the compressive side of the tree.

(2) Maximum stresses and curvatures for reinforced stems (supported by FRP wraps) are significantly reduced in the reinforced areas, especially when the midpoints of the FRP wraps are located at $h=1.2 \mathrm{~m}$.

(3) Increasing the number of FRP layers reduces the stress on the stem. These efficiencies decrease, however, as the number of layers increases beyond $n=3$.

(4) Although increasing the FRP wrapping width can mitigate the stress concentrations on the edges of the FRP wraps, the stresses at the midpoints increase inversely; as the width of an FRP wrap increases, the burden on the edges decreases but the efficiency of the resulting stress reduction rates declines. A $1 \mathrm{~m}$ width for the FRP wraps was found to be the most effective.

(5) The tree's ultimate strength is increased most effectively when the FRP wrap is located at breast height $(h=1.2 \mathrm{~m})$.

(6) The yield points occurred at approximately $0.002 \mathrm{rad} / \mathrm{m}$ in most cases.

The findings of this study indicate that the stability of a tall, old tree can be indirectly evaluated using information on its curvature. The outcomes from this study could thus be utilized to develop a set of guidelines to support efforts to enhance the structural stability of large, old large trees of 


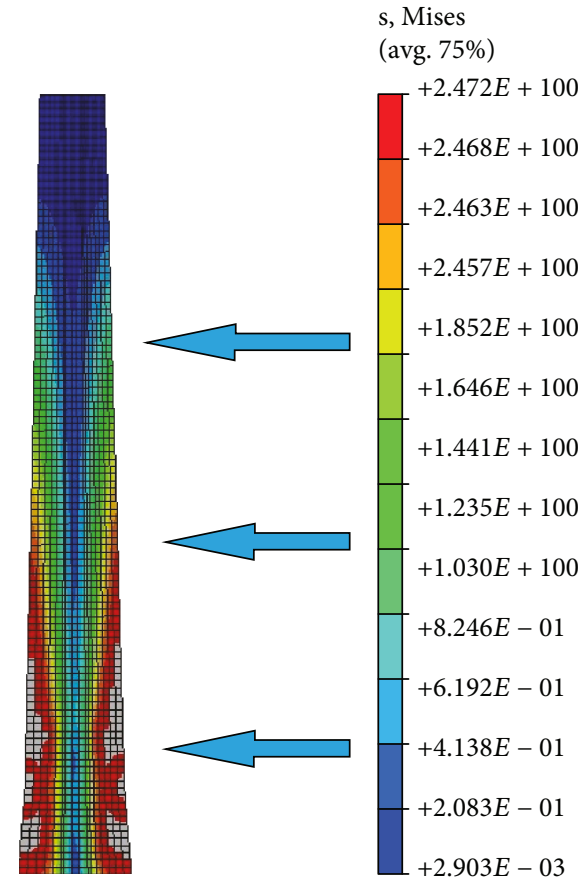

(a) Stem

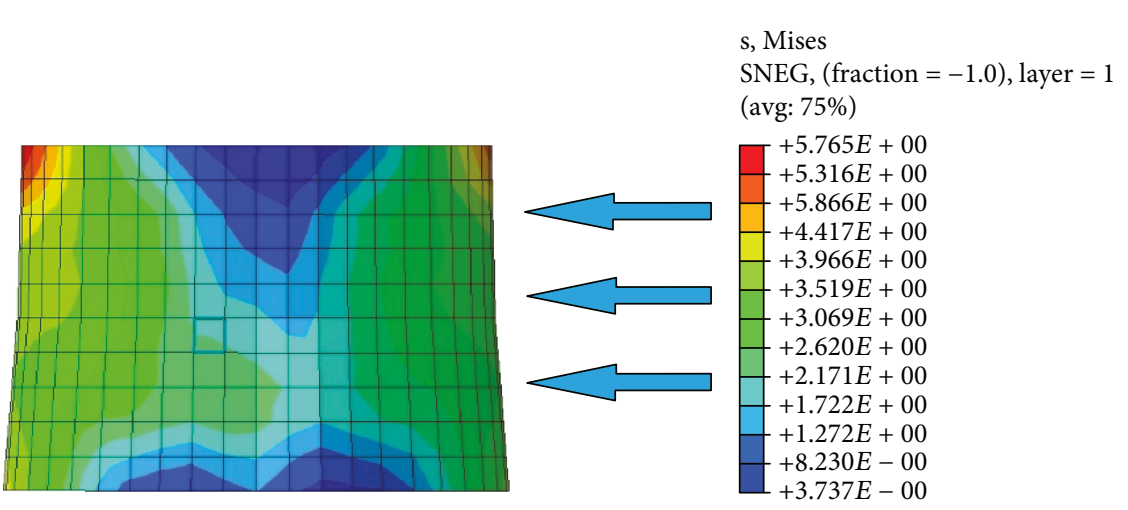

(b) FRP wraps

Figure 13: Stress contours when yielding occurs in the stem: (a) stem and (b) wrap.

historical importance such as Jung-yi-pum-song that are vulnerable to the high winds that typically accompany severe weather events in the Korean peninsula.

\section{Data Availability}

The data used to support the findings of this study are available from the corresponding author upon request.

\section{Conflicts of Interest}

The author declares that he has no conflicts of interest.

\section{Acknowledgments}

This work was supported by the Research Resettlement Fund for new faculty at Seoul National University (Project no. 500-20170077) and a grant from the Ministry of Land, Infrastructure and Transport (MOLIT) of the Korean Agency for Infrastructure Technology Advancement (KAIA) (18CTAP-C132633-02).

\section{References}

[1] NRICH (National Research Institute of Cultural Heritage), $A$ Study for the Appropriateness and Stability for the Protection Facility of Natural Monument Tree. Project No. NRICH-1407B17F, Seoul National University (PI: Sung-Kyun Kim), 2014.

[2] K. James, C. Hallam, and C. Spencer, "Tree stability in winds: measurements of root plate tilt," Biosystems Engineering, vol. 115, no. 3, pp. 324-331, 2013.

[3] H. Peltola, S. Kellomaki, H. Vaisanen, and V. Ikonen, "A mechanistic model for assessing the risk of wind and snow damage to single trees and stands of Scots pine, Norway spruce, and birch," Canadian Journal of Forest Research, vol. 29, no. 6, pp. 647-661, 1999.

[4] B. Gardier, H. Peltora, and S. Kellomäki, "Comparison of two models for predicting the critical wind speeds required to damage coniferous trees," Ecological Modelling, vol. 129, no. 1, pp. 1-23, 2000.

[5] T. Locatelli, B. Gardiner, S. Tarantola et al., "Modelling wind risk to Eucalyptus globulus (Labill.) stands," Forest Ecology and Management, vol. 365, pp. 159-173, 2016.

[6] K. A. Anyomi, S. J. Mitchell, A. H. Perera, and J. Ruel, "Windthrow dynamics in boreal Ontario: a simulation of the vulnerability of several stand types across a range of wind speeds," Forests, vol. 8, no. 7, p. 233, 2017.

[7] E. Brudi and P. van Wassenaer, "Trees and statics: nondestructive failure analysis," in Tree Structure and Mechanics Conference Proceedings: How Trees Stand Up and Fall Down, pp. 53-69, Champaign, IL, USA, 2002.

[8] C. J. Peterson and V. Claassen, "An evaluation of the stability of Quercus lobata and Populus fremontii on river levees assessed using static winching tests," Forestry, vol. 86, no. 2, pp. 201209, 2012

[9] M. Yang, P. Dèfossez, F. Danjon, and T. Fourcaud, "Tree stability under wind: simulating uprooting and root breakage using a finite element method," Annals of Botany, vol. 114, no. 4, pp. 695-709, 2014.

[10] Y. Chiba, "Modelling stem breakage caused by typhoons in plantation Cryptomeria japonica forests," Forest Ecology and Management, vol. 135, no. 1-3, pp. 123-131, 2000.

[11] K. R. James, N. Haritos, and P. K. Ades, "Mechanical stability of trees under dynamic loads," American Journal of Botany, vol. 93, no. 10, pp. 1522-1530, 2006. 
[12] A. Parvin and T. S. Shah, "Fiber reinforced polymer strengthening of structures by near-surface mounting method," Polymers, vol. 8, no. 8, p. 298, 2016.

[13] J. Zhao, G. Cai, L. Cui, A. S. Larbi, and K. D. Tsavdaridis, "Deterioration of basic properties of the materials in FRPstrengthening RC structures under ultraviolet exposure," Polymers, vol. 9, no. 12, p. 402, 2017.

[14] E. T. Smiley and K. D. Coder, Tree Structure and Mechanics Conference Proceedings: How Trees Stand Up and Fall Down, International Society of Arboriculture, Campaign, IL, USA, 2002.

[15] Dassault Systemes, Abaqus, 2016.

[16] Cultural Heritage Administration, Survey Report on Natural Heritage-primary Old and Large Trees in South Korea, Cultural Heritage Administration, 2007, Document No. EM037956.

[17] “Wikipedia," 2018, https://en.wikipedia.org/wiki/Orthotropic_ material.

[18] A. Bertram and R. Gluge, Solid Mechanics: Theory, Modeling, and Problems, Springer, 2013.

[19] R. J. Ross, "Wood handbook : wood as an engineering material," General technical report FPL, GTR-190, Department of Agriculture, Forest Service, Forest Products Laboratory, Madison, WI, USA, Centennial edition, 2010.

[20] Y. Ou and D. Zhu, "Tensile behavior of glass fiber reinforced composite at different strain rates and temperatures," Construction and Building Materials, vol. 96, pp. 648-656, 2015.

[21] The European Union, EN 1993-3-1: Design of Steel Structures Towers, Masts and Chimneys - Towers and Masts, European Committee for Standardization, 2006.

[22] Korea Meteorological Administration, Typhoon white book, 2011, NO. 11-1360016-000001-01.

[23] J. A. Petty and C. Swain, "Factors influencing stem breakage of conifers in high winds," Forestry, vol. 58, no. 1, pp. 75-84, 1985. 


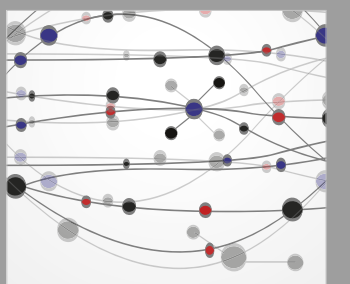

The Scientific World Journal
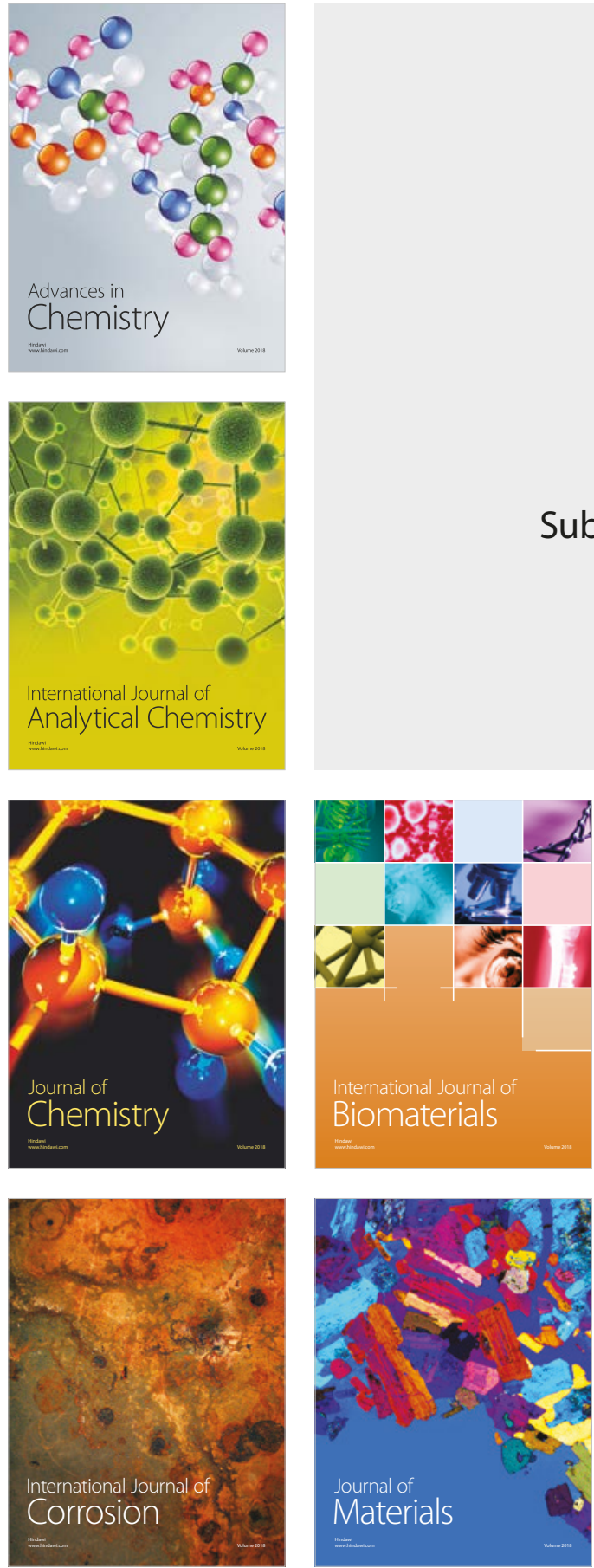

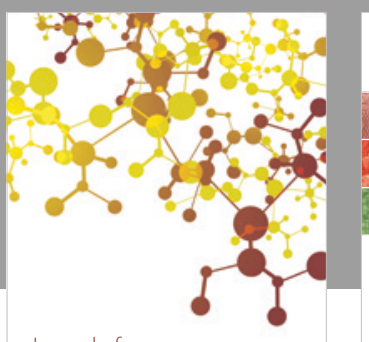

Journal of

Applied Chemistry
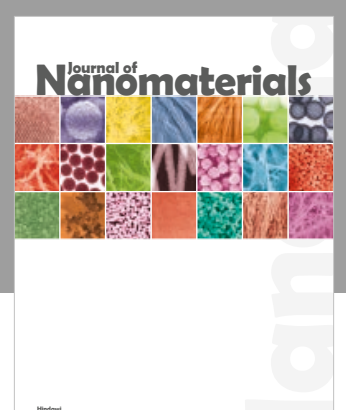

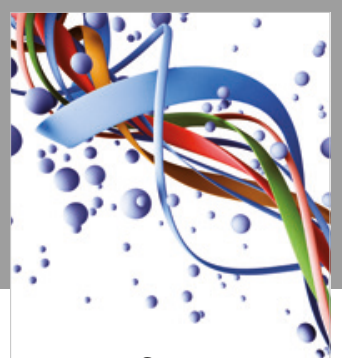

Scientifica

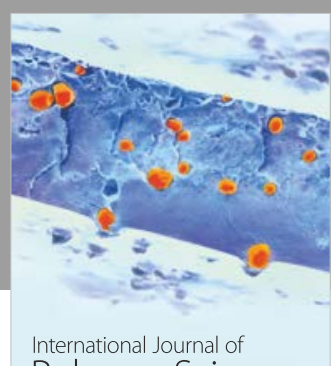

Polymer Science

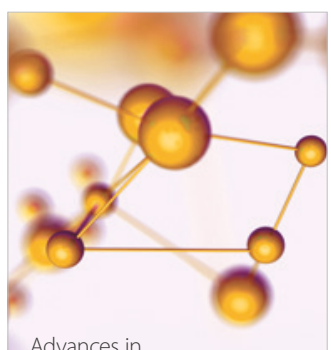

Physical Chemistry
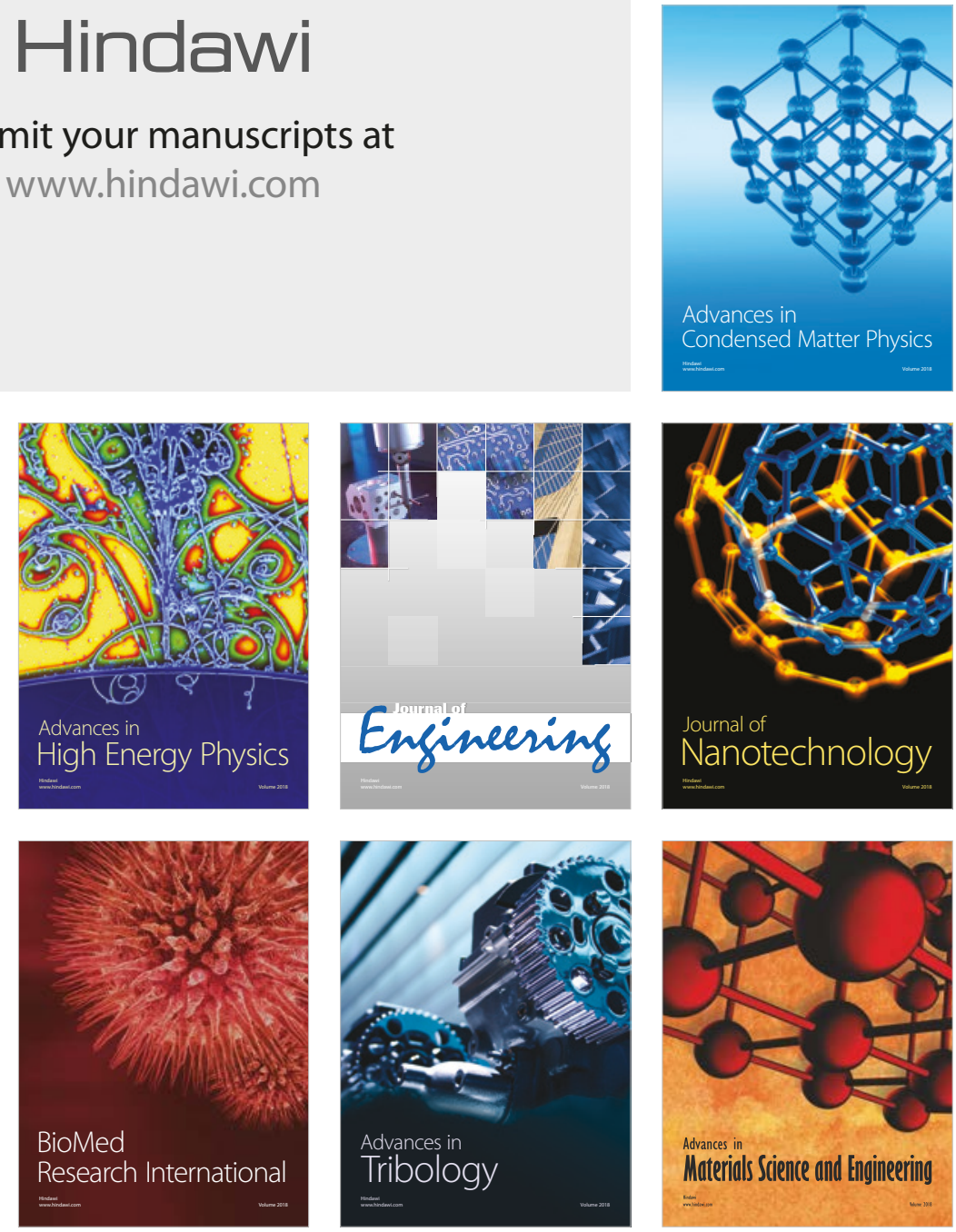